\title{
4 Aspect
}

The focus of this chapter is the interaction of aspect with definiteness. Before discussing this, I will provide a short introduction to the semantics of aspect and how it is morphologically expressed in Polish in 4.1 and 4.2, respectively. In order to account for the data presented in section 4.3, I will discuss the notion of incremental theme verbs in 4.4 and in 4.5 I will look at additional Polish data to investigate further criteria that influence definiteness. Section 4.6 focuses on the connection between aspect, definiteness, and the concept type approach by Löbner.

\subsection{The semantics of aspect}

First of all, grammatical aspect has to be distinguished from lexical aspect (Filip 1993/1999, Borik 2006: 21f., Richardson 2007: 5, 9f., Gvozdanović 2012: 781f.). 'Lexical aspect' is an inherent property of verbs and has to be distinguished from aspectual classes which also include verb phrases and sentences according to Filip (2012: 725):

Although "lexical aspect" is also used to refer to the aspectual class of verb phrases (cf. e.g., van Hout, 2003) and sentences, this use is, strictly speaking, incorrect and should be avoided. The notion of aspectual class is a wider notion than that of lexical aspect, subsuming lexical aspect as a special case when just verbs, taken as lexical items, are at stake. Aspectual class is to be distinguished from aspectual form (see also Dowty, 1979, p. 52, following Johnson, 1977), whereby the latter concerns the expression of grammatical aspect. In contrast to aspectual form (grammatical aspect), aspectual class need have no overt marker and may remain as an intrinsic semantic property of verbs, verb phrases and sentences. (Filip 2012: 725) 
The term 'lexical aspect' is often (and misleadingly) used for Vendler's (1957) four-way distinction between states (know, love), activities (rain, run), achievements (arrive, burst) ${ }^{1}$, and accomplishments (build a house, run a kilometre). As the examples show, what we have are aspectual classes since VPs are involved. A fifth class, namely semelfactives, may also be added (Smith 1991: 28). These five classes can be distinguished by the following three semantic properties: 'dynamicity' means that a change is involved, 'durativity' that the event is temporally extended, and 'telicity' ${ }^{2}$ means that there is an inherent endpoint that is reached (Comrie 1976, chapter 2; Fleischhauer 2016: 68f.). ${ }^{3}$ Table 11 illustrates the semantic features and the five verb classes:

\begin{tabular}{l|l|l|l} 
Verb classes & dynamic & durative & telic \\
\hline State & no & yes & no \\
\hline Activity & yes & yes & no \\
\hline Achievement & yes & no & yes \\
\hline Accomplishment & yes & yes & yes \\
\hline Semelfactives & yes & no & no
\end{tabular}

Table 11: Verb classes and their distinguishing properties (Fleischhauer 2016: 68).

What states and activities have in common is that they are not telic, in contrast to achievements and accomplishments. States can be distinguished from activities since they are not dynamic. Finally, achievements differ from accomplishments in that they are not durative but punctual. Semelfactives ${ }^{4}$ such as knock differ from activity verbs only in

$1 \quad$ Verbs such as burst and explode are not given by Vendler (1957) as examples of achievements, but they are counted here as achievements, too.

2 The telic/atelic distinction was coined by Garey (1957: 106).

3 Beside the endpoint approach to telicity, there is also another notion of telicity, namely the homogeneity approach. In this approach, predicates are telic if they "refer to eventualities which are not viewed as having subparts" (Borik 2006: 37). For a detailed discussion of the two approaches see Borik (2006).

As Filip (2012: 727) notes "drawing the lines between aspectual classes is controversial”. Semelfactives are atelic for Smith (1991: 28, 55ff.) but telic for Mourelatos (1978). 
that they are punctual. ${ }^{5}$ Tests are proposed in the literature to distinguish between the different aspectual classes, see Dowty (1979: 55f.) for a summary of the tests. ${ }^{6}$ Since the distinction between telic and atelic predicates will be important in this chapter, one very common test will be discussed here. ${ }^{7}$ If atelic predicates are combined with time span adverbials such as in an hour they can only have the reading that the event starts in an hour. This ingressive reading is also available with telic predicates. However, telic predicates also allow for an egressive reading, i.e. that the event is finished within an hour. In (1a), the time span adverbial can be added to express that the car was fixed after working on it for one hour, which shows that this predication is telic while in (1b) such an interpretation is not possible showing that (1b) is atelic.

a. Mary repaired the car in an hour.

b. Mary watched TV in an hour.

Grammatical aspect, in contrast to lexical aspect, is a grammatical category which expresses the opposition between perfective and imperfective. Grammatical aspect has to do with the "different ways of viewing the internal constituency of a situation" (Comrie 1976: 3). This means that grammatical aspect is about how we look at situations, which is not the case with lexical aspect. Let me first present Comrie's classification of grammatical aspect shown in figure 2 and then present a critical evaluation of its weaknesses.

Fleischhauer (2016: 69) points out that verbs such as knock "are ambiguous between a semelfactive - single event reading - and an activity reading. In their activity reading these verbs denote an iteration of single events". progressive as well as the possible combination with for-, in-, and, at-adverbials.

A summary of the telicity tests mentioned in the literature is given in Filip (1993/1999: 19f.). 


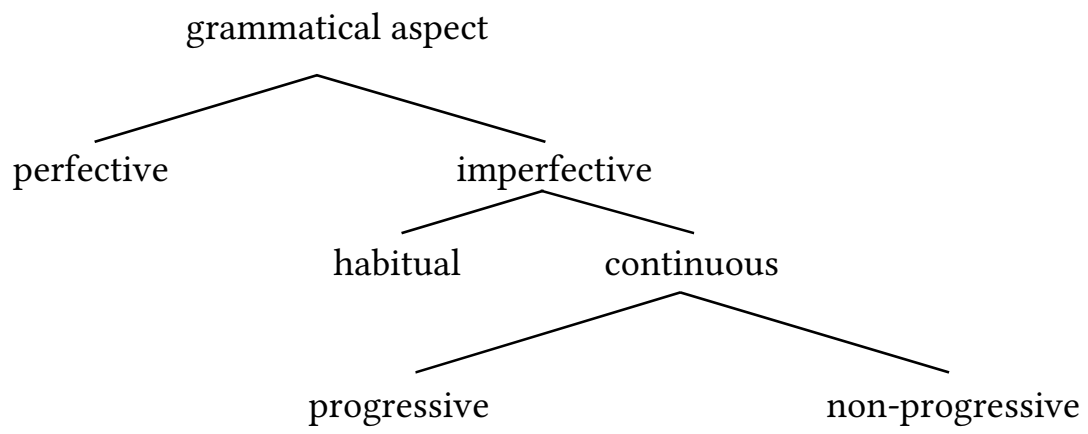

Figure 2: Subdivision of grammatical aspect (Comrie 1976: 25).

Grammatical aspect is subdivided into perfective and imperfective aspect. Perfective means that "the situation is presented as a single unanalysable whole" and that "no attempt is made to divide this situation up into the various individual phases" (Comrie 1976: 3). Thus, perfective aspect denotes a complete event. To illustrate this, a Polish example is given in (2). ${ }^{8}$ By using the perfective verb kupit the speaker expresses that the action of buying the/a book is viewed as a completed event.

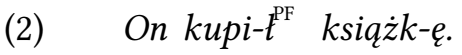

he buy-PST book-ACC

'He bought a/the book.'

The habitual aspect, subsumed by Comrie under imperfective aspect, describes a situation "which is characteristic of an extended period of time, so extended in fact that the situation referred to is viewed not as an incidental property of the moment but, precisely, as a characteristic feature of a whole period" (Comrie 1976: 27f.), which can be expressed in English by the construction 'used to + infinitive' as in (3).

(3) He used to play football.

Filip \& Carlson (1997: 98f.) argue that the habitual (or generic) aspect should be regarded as independent of aspect and thus should not be clas-

The grammatical aspect is superscripted to the verb in (2) and not given in the glossing. The reason for doing so will be explained in section 4.2. 
sified as a special case of imperfective aspect. One argument they present is that perfective verbs can also express habituality/genericity, which they illustrate by Czech and Russian examples. The Polish example in (4) demonstrates the same point. Although we have the perfective verb przepalic' 'smoke', habituality is expressed, which is enforced by the presence of the adverbial codziennie 'every day'.

$$
\begin{array}{ll}
\text { fa codziennie prze-pal-ę } & 20 \text { papieros-ów. } \\
\text { I every_day PRZE-smoke-1SG.PRS } 20 \text { cigarette-PL.GEN } \\
\text { 'I smoke } 20 \text { cigarettes every day.' (Lenga 1976: 46) }
\end{array}
$$

The perfective verb przepalić in (4) can be replaced by the imperfective verb przepalać without changing the habitual reading in (4). This shows that habituality can be expressed by perfective and imperfective verbs and that "habituality and aspect, perfective and imperfective, are notionally orthogonal to each other" according to Filip \& Carlson (1997: 99).

In contrast to perfective aspect, the imperfective aspect has an "explicit reference to the internal temporal constituency of the situation" (Comrie 1976: 4) and the situation is looked at from within. Imperfective aspect is a cover term for the continuous and habitual aspect according to Comrie. The continuous aspect is defined by Comrie (1976: 26) negatively as "imperfectivity that is not habituality". Filip \& Carlson (1997: 100) argue that the continuous node is gratuitous in Comrie's figure. According to them, imperfective verbs with a progressive or non-progressive reading also allow for a habitual interpretation. This is why there is no language that has a notional or formal category of continuous aspect. According to Comrie, the continuous aspect subsumes the progressive and non-progressive aspect. With the progressive aspect, the situation is described as ongoing; in contrast to the non-progressive aspect which describes situations as non-dynamic. (5) is an example of progressive aspect in English and (6) exemplifies non-progressive aspect. (5) also shows that progressive aspect is grammaticalized in English since the construction 'be + verb-ing' has to be used.

(5) He is eating an apple.

(6) He lives in London. 
Filip (2001: 468) shows that an imperfective verb can have several readings. She illustrates this with a Russian example, but her observation also applies to Polish:

(7) Russian (Filip 2001: 468)

Ivan jel ${ }^{\mathrm{MPF}}$ jábloko.

Ivan eat.PST apple.SG.ACC

(i) 'Ivan was eating an/some/the apple.' (progressive reading)

(ii) 'Ivan ate at an/some/the apple.' (partitive reading)

(iii) 'Ivan ate all the apple/the whole apple.'(completive reading)

(iv) 'Ivan ate an/some/the apple.' [and did (not) finish eating it] (general factual reading)

(v) 'Ivan repeatedly ate an/some apple.' (iterative reading)

(vi) 'Ivan used to eat an/some apple.' (generic/habitual reading)

Imperfective verbs with a completive reading overlap with the function of the perfective verb and as Filip (2001) points out "[i]n such cases, it may be preferable to use the corresponding perfective verb forms in both Russian and Polish" (Filip 2001: 469, footnote 17). The general factual reading (also called 'simple denotative') is used if "the speaker is simply interested in expressing the bare fact that such and such an event did take place, without any further implications, and in particular without any implication of progressive or habitual meaning" (Comrie 1976: 113).

According to Borik (2006: 202ff.), the imperfective aspect in Russian also corresponds to the present perfect in English. There are different types of perfect (for a detailed discussion see Comrie 1976, chapter 3). One type is the perfect of result, which is expressed by the present perfect in English (Borik 2006: 202). Here, the present situation is the result of a past event (Comrie 1976: 56). In Polish too, the imperfective verb can express the perfect of result as in (8). The present situation, namely that the person stinks out of his/her mouth, results from eating garlic in the past. The perfect of result can be expressed with the imperfective verb jeść 'eat'. 
(8)

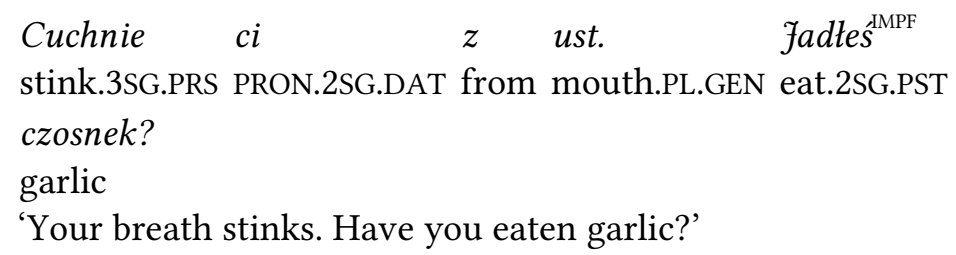

In (8), the perfective verb zjeść 'eat' can also be used for a perfect reading. However, the imperfective verb is preferred. In the following, the perfect reading of perfective and imperfective verbs in Polish will not be considered. Furthermore, I will only give the progressive and general factual reading of imperfective verbs in the English translations and neglect the other possible readings.

\subsection{Morphological realization of grammatical aspect in Polish}

There is a lot of literature on grammatical aspect in Polish, in Slavic, and in general (Isačenko 1962, Forsyth 1970, Czochralski 1975, Comrie 1976, Filip 1993/1999, Dickey 2000, Borik 2006, Gvozdanović 2012, among many others). Simplex verbs, i.e. verbs with no affixes, can be either perfective or imperfective in Polish. ${ }^{9}$ There are several tests which can be applied to determine whether a verb is perfective or imperfective (cf. Filip 1993/1999: 178f.).

Phase verbs like (s)kończyć 'to finish', aczynac $^{\mathrm{IMPF}} /$ zaczac $^{\mathrm{PF}}$ 'to begin' or przestawac ${ }^{\text {IMPF }} /$ przestac $^{\mathrm{PF}}$ 'to stop' can only be combined with imperfective verbs in Polish. The combination with perfective verbs is ungrammatical as in (9).

There is only a small number of Polish verbs that are biaspectual. Depending on the context they are imperfective or perfective. Verbs such as pitrasić 'cook (coll.)', potrafić 'be able, manage', powozić 'drive (horse-drawn vehicle)' belong to this class according to Swan (2002: 280). The biaspectual status of, for example, pitrasić 'cook (coll.)' is, however, questionable since applying the tests given in (9) - (11) it is imperfective. Furthermore, there is a prefixed perfective counterpart upitrasić. Loan words of the kind kategoryzować 'categorize' and organizować 'organize' are imperfective in Polish and can be perfectivized by the prefixes $s$ - and $z$-, respectively. 
(9) Jan skończy- $t^{\mathrm{PF}}$ jeśc $^{\mathrm{IMPF}} /{ }^{*} z j e s c^{\mathrm{PF}}$.

Jan finish-PST eat

'Jan finished eating.'

The second test which can be applied has to do with the fact that, in Polish, only imperfective verbs can be combined with the analytic future form consisting of the auxiliary być 'to be' and the infinitive (10):

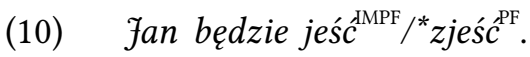

Jan AUX eat

'Jan will eat.'

The third test is connected to the second one since perfective verbs in the present tense do not have a present, but a future time reading while imperfective verbs have a present time reading (11).
a. Jan $z$-je $e^{\mathrm{PF}} \quad$ jabtk-o.
Jan Z-eat.3SG.PRS apple-ACC
'Jan will eat the/an apple.'
b. $\quad$ fan $j e^{\mathrm{IMPF}} \quad$ jabtk-o.
Jan eat.3SG.PRS apple-ACC
'Jan is eating the/an apple.'

The three tests, which are summarized in table 12 , reveal that the verb $z j e s s c ́$ ' to eat' is perfective while jeść 'to eat' is imperfective.

\begin{tabular}{|l|l|l|}
\hline test & perfective & imperfective \\
\hline Combination with phase verbs & no & yes \\
\hline $\begin{array}{l}\text { Combination with the future auxiliary } \\
\text { byc 'be' }\end{array}$ & no & yes \\
\hline $\begin{array}{l}\text { Present tense allows only a future } \\
\text { time reading }\end{array}$ & yes & no \\
\hline
\end{tabular}

Table 12: Summary of the tests to determine the (im)perfectivity of verbs.

There is a strategy of imperfectivizing perfective verbs by adding the suffix $-(i / y) w a$, which only changes the grammatical aspect (12). This 
process is called 'secondary imperfectivization'. The suffix can be added to a perfective simplex verb (12a) or to a verb which is perfective due to a prefix such as pod-in (12b). (12c) shows that secondary imperfectivization is not possible with all Polish perfective verbs.
a. $\quad$ kupic $^{\mathrm{PF}}-$ kupowac $^{\mathrm{IMPF}}$
b. pod-pisac $^{\mathrm{PF}}$ - pod-pisywac $^{\mathrm{IMPF}}$
'buy'
c. $\quad n a-p i s a c^{P F}-{ }^{*} n a-p i s y w a c ́$
'sign'
'write'

Other aspectual pairs are formed by suppletive forms (13): ${ }^{10}$
a. $\quad \operatorname{rrac}^{\mathrm{IMPF}}-$ wziac $^{\mathrm{PF}}$ 'take'
b. mówic $^{\mathrm{IMPF}}$ - powiedziec ¿P $^{\mathrm{F}}$ 'speak'

In Polish and in other Slavic languages, imperfective verbs can be perfectivized by the use of prefixes. Wróbel (1998: 539) gives a list of all prefixes in Polish (14):

$$
\begin{aligned}
& \text { do-, na-, nad(e)-, o-/ob(e)-, od(e)-, po-, pod(e)-, prze-, przy-, } \operatorname{roz}(e)^{-} \text {, } \\
& u-, w(e)^{-}, w(e) z-/ w(e) s^{-}, w s p o ́ t-, w y^{-}, z(e)^{-/} / s^{-} / s^{-}, z a-\text {. }
\end{aligned}
$$

In (15), three imperfective verbs are given which are perfectivized by the prefixes $n a$-, prze-, and $z$ - (15). In (15), the verbs only differ in the verbal aspect and not in their meaning.
a. pisac $\hat{c}^{\mathrm{MPF}}$
napisac $^{\mathrm{PF}}$
'write'
b. czytac $^{\text {MPF }}$
przeczytac $^{\mathrm{PF}}$
'read'
c. $\quad$ jeśc $c^{\lambda \mathrm{MPF}}$
$z j e s c^{\mathrm{PF}}$
'eat'

Verbal prefixes can also be combined with already prefixed verbs and thus prefix stacking is possible. ${ }^{11}$ This is illustrated in (16), where the distributive $p o$ - can be prefixed to an already prefixed verb adding the meaning 'one by one'.

\footnotetext{
10 There are imperfectives with no perfective counterpart such as mieć 'have', należeć 'belong to', umieć 'know' and perfective verbs such as ujrzeć 'see, behold', zdołać 'manage to do sth', zaniemówić 'be speechless' that do not have an imperfective counterpart (Bartnicka et al. 2004: 403).

Bulgarian allows up to seven prefixes to be attached to the verb at the same time (Istratkova 2004: 309).
} 
Po-roz-rzucata ${ }^{\mathrm{PF}}$ wszystkie koszule na podtodze.

DISTR-ROZ-threw all shirts on floor

'She threw each and every one of the shirts on the floor.'

(Swan 2002: 289)

I follow Filip (1993/1999: 9, 13, 200), for whom the verbal prefixes are derivational since they not only perfectivize an imperfective verb, but often have a semantic effect on the verb and thus derive new (perfective) verbs. Authors also distinguish between empty, lexical, and superlexical prefixes (cf. Richardson 2007: 53, Gehrke 2008a, 2008b: 161f., Gvozdanović 2012: 782f.). In (17a), the addition of the prefix na- does not change the meaning of the imperfective verb pisać, but only renders the verb perfective. This is why some prefixes are sometimes called 'empty prefixes' in the combination with certain verbs with which only the aspect is changed (Młynarczyk 2004). In contrast, the prefix pod- in (17b) has an effect on the meaning of the verb pisać 'to write' in addition to the change of grammatical aspect. Such prefixes are called 'internal' or 'lexical prefixes' due to the fact that they derive new verbs. Gehrke (2008a, 2008b: 171), among others, argues that internal prefixes induce telicity, whereas external (also called 'superlexical') prefixes are orthogonal to telicity. External prefixes specify the action of the verb concerning time and intensity. For example, the delimitative prefix po- in $(17 \mathrm{c})$ adds the information that the writing event takes place for a while. ${ }^{13}$
pisac ${ }^{\mathrm{MMF}} \quad$ 'write'
a. napisac ${ }^{\mathrm{PF}}$ 'write'
b. podpisac ${ }^{\mathrm{PF}}$ 'sign'
c. popisac 'write for a while'

Among others, Gehrke (2008a: 1668f., 2008b: 161f.) provides four criteria to distinguish internal from external prefixes. First, internal prefixes can effect the argument structure of the verb such as the addition or deletion of an argument, which is not the case with external prefixes. Second, internal prefixes allow secondary imperfectivization, whereas external prefixes do not. Third, verbs with internal prefixes can derive complex event nominal, while this is not possible with externally prefixed verbs. Fourth, only external prefixes can be attached to already prefixed verbs. 
Consequently, prefixes are not in general markers of perfectivity. The only true aspectual marker is $-(i / y) w a$, which marks imperfectivity. Due to the reasons mentioned above, the grammatical aspect of the verbs will be indicated by superscripts and not in the glossings.

\subsection{The interaction of aspect and definiteness}

For Russian, it is well known that aspect can have an influence on the definiteness of the direct object (cf. Forsyth 1970: 91f., Birkenmaier 1979: 112f., Chvany 1983: 71, Filip 1993/1999: 11, 233, Leiss 2000). In (18a), the verb is perfective while in (18b) we have an imperfective verb. The direct object has only a definite reading in (18a), in contrast to the definite or indefinite interpretation in (18b).

(18) Russian

a. On s'-el PF $^{\mathrm{PF}} \quad$ ablok-i

he S-eat.PST apple-ACC.PL

'He ate the apples.'

b. On el $l^{\mathrm{MPF}}$ jablok- $i$

he eat.PST apple-ACC.PL

'He ate/was eating (the) apples.'

On the basis of Slavic data such as in (18), some authors - such as Leiss (2000) and Borer (2005) - argue that articleless languages, like the majority of the Slavic languages, express definiteness with the perfective/imperfective distinction while in Germanic this is expressed by the definite and indefinite article. Leiss (2000) explicitly claims that the perfective aspect and the definite article express the same grammatical category on the verb in Slavic languages and inside the object NP in the Germanic languages. Arguments against this view will be presented in this chapter.

Wierzbicka (1967) was one of the first to describe the interaction of grammatical aspect with definiteness of the direct object in Polish. Wierzbicka (1967: 2237f.) argues that due to the perfective verb in (19a) 
the direct object is best translated with a definite article in contrast to (19b), where only an indefinite reading is possible for Wierzbicka.
a. On wy-pit $\quad$ wod-e
he WY-drink.PST water-ACC
'He drank (all) the water'
b. On pit ${ }^{\mathrm{MPF}}$ wod-e
he drink.PST water-ACC
'He was drinking water'
(Wierzbicka 1967: 2237)

Wierzbicka contributes to the discussion on aspect and definiteness by showing that for perfective verbs a definite direct object is only enforced with bare plural and mass nouns, but not with count nouns. Krifka (1989: 186) formulates this condition explicitly on the basis of Wierzbicka's research on Polish, Birkenmaier's (1979) research on Russian, and Filip's (1985) research on Czech. The bare singular count noun truskawka 'strawberry' combined with a perfective verb as in (20a) can have a definite or indefinite reading. If the direct object is not bare, but used with, for example, the quantifier kilka 'a few ${ }^{14}(20 \mathrm{~b})$ the direct object is not definite.
a. Jan $z$-jadt $t^{\mathrm{PF}}$ truskawk-e.
Jan Z-eat.PST strawberry-SG.ACC
'Jan ate a/the strawberry.'
b. Jan $z$-jadt $\mathrm{P}^{\mathrm{F}}$ kilka truskawek.
Jan Z-eat.PST a few strawberry.PL.GEN
'Jan ate a few strawberries.'

For Krifka (1989: 186) as well as Wierzbicka (1967), the direct object of an imperfective verb can only have an indefinite interpretation. Filip (1992, 1993/1999: 10, and elsewhere) points out that in examples like (19b), the bare mass noun woda 'water' can be definite or indefinite. She shows that the imperfective aspect cannot automatically be associated with

14 The quantifier kilka requires the direct object to be in the genitive case. 
indefiniteness. Filip gives a fully fledged account of this phenomenon, which will be discussed in detail in the next section.

So far, it has been shown that there are perfective verbs which enforce definiteness of a bare plural or mass noun as direct object. However, the question is whether this effect is observable with all perfective verbs. For Polish, Piñón (2001) states "[i]f a verb is perfective, then it cannot have a syntactically bare plural or singular mass noun phrase argument that receives a bare plural or bare singular mass interpretation" (Piñón 2001: 399) but is only "acceptable if the bare noun phrase is understood to be definite" (Piñón 2001: 398). Nevertheless, at the end of his article he admits "that not all perfective verbs in Polish exhibit the restriction [...]. This is imaginable, even if clear counterexamples are rather hard to detect" (Piñón 2001: 414). (21a) shows that in Polish the perfective verb zjeść 'eat' also only allows for a definite reading of the direct object trus$k a w k i$ 'strawberries'. However, (21b) illustrates that this is not the case with all perfective verbs since the direct object truskawki can also have an indefinite reading with the perfective verb kupic 'buy'.
a. On $z$-jadt $t^{\mathrm{PF}}$ truskawk-i.
he Z-eat.PST strawberry-PL.ACC
'He ate (all) the strawberries.' (Wierzbicka 1967: 2238)
b. On kupi- $\mathrm{I}^{\mathrm{F}}$ truskawk-i.
he buy-PST strawberry-PL.ACC
'He bought (the) strawberries.'

The context may enforce the definite or indefinite reading of the direct object in (21b). The same holds for singular count nouns as direct objects or direct objects of imperfective verbs. Other strategies such as information structure can be used in order to indicate that the direct object is definite. This is shown by example (22a), in which the singular count noun truskawka 'strawberry' is the unstressed preverbal direct object and only allows for a definite interpretation due to the fact that it is the topic of the sentence. ${ }^{15}$ The same applies to the plural noun truskawki 'strawberries' as the direct object of an imperfective verb (22b).

15 Information structure will be discussed in detail in chapter 6 . 
(22)
a. Truskawk-e $z$-jadt ${ }^{\mathrm{PF}}$ fAN.
strawberry-SG.ACC Z-eat.PST Jan
'Jan ate the strawberry.'
b. Truskawk-i jadt ${ }^{\mathrm{MPF}}$ FAN.
strawberry-PL.ACC eat.PST Jan
'Jan ate/was eating the strawberries.'

The definite interpretation can also be enforced by a determiner (23):
a. Jan $z$-jadt tę truskawk-ę.
Jan Z-eat.PST DEM strawberry-SG.ACC
'Jan ate this strawberry.'
b. Fan jadt ${ }^{\mathrm{MPF}}$ te truskawk-i.
Jan eat.PST DEM strawberry-PL.ACC
'Jan ate/was eating these strawberries.'

My own observation shows that there are also other verbs than wypic ${ }^{\mathrm{PF}}$ 'drink' and $z j e s c^{\mathrm{PF}}$ 'eat' with which this definiteness enforcement persists, such as the Polish verb skosić 'mow'. The following examples show that we get a definite reading with the perfective verb skosić while a definite or indefinite reading is possible with the imperfective verb kosić.
a. Jan s-kosi- $\mathbb{P}^{\mathrm{PF}} \quad$ traw-ę.
Jan S-mow-PST grass-ACC
'Jan mowed the grass.'
b. Jan kosi- $\ell^{\mathrm{MPF}}$ traw-ę.
Jan mow-PST grass-ACC
'Jan mowed/was mowing (the) grass.'

The question now arises under which conditions and with which verbs perfective aspect has an effect like in (24a). The verbs eat, drink, mow which were discussed in this section are all incremental theme verbs. With these verbs, only a definite interpretation of the bare cumulative direct object argument can be found. We do not see the effect of aspect with the verb buy in (21b). Since incremental theme verbs seem to be an explanatory factor, it will be the topic of the next section. 


\subsection{Incrementality}

\subsubsection{Incremental theme verbs}

The notion of incremental theme verbs such as eat, drink, mow was introduced by Krifka (1986, 1989: 158f., 1992, 1998). Krifka differentiates between "Sukzessiv-Patiens" and "Simultan-Patiens" in order to distinguish the semantic relations of the object of the German verbs sehen 'see' and trinken 'drink'. He defines the two relations as follows:

Bei trinken wird das Objektdenotat nach und nach dem Ereignis unterzogen; ich nenne die Relation daher Sukzessiv-Patiens [...]. Bei sehen ist es hingegen möglich, daß das Objektsdenotat simultan dem Verbereignis unterzogen wird; ich nenne es daher Simultan-Patiens (Krifka 1989: 161)

[With drink, the object referent is gradually subjected to the event; this is why I call this relation the gradual patient [...]. With see, however, it is possible that the object referent is simultaneously subjected to the event; this is why I call it the simultaneous patient]

What Krifka calls 'Sukzessiv-Patiens' was later called 'incremental' by Dowty (1991: 567). With incremental theme verbs, the referential properties of the direct object have an influence on the telicity of the whole predication. There are three types of incremental theme verbs: (i) verbs of consumption (eat, drink, smoke), (ii) verbs of creation/destruction (build, write, burn, destroy), and (iii) verbs of performance (sing, read) (Krifka 1989: 158f., Dowty 1991: 568f.).

Incremental theme verbs provide a homomorphic mapping between the incremental theme argument and the event. The mapping to subevents and mapping to sub-objects are two requirements for the definition of the homomorphism (Krifka 1998: 211f.). Taking an example such as Mary ate a tomato, these two requirements ensure that every proper part of the tomato which is consumed is mapped to a part of the eating event and every part of the eating event is mapped to a proper part of the tomato. 
The progress of the eating event is measured out by the incremental theme argument. ${ }^{16}$ When half of the tomato is consumed, half of the event is over. When the entire tomato is eaten, then the event is finished. And vice versa, i.e. when half of the eating event is over, then half of the tomato is eaten and when the whole event is over, the tomato is completely consumed.

For the definition of strictly incremental theme verbs such as eat and drink the uniqueness of the events and the uniqueness of the objects have to be fulfilled (Krifka 1998: 212). These conditions ensure that there is exactly one event to which the object is mapped and that there is only one object the event is mapped to.

Given the introduction of all four conditions for strict incrementality by Krifka (1998), it becomes obvious that only verbs of consumption (eat, drink, smoke) and verbs of creation/destruction (build, write, burn, destroy) fulfil all of them. Verbs of performance (sing, read) do not since despite the fact that they express a gradual change of state, two distinct subevents of, for example, reading can be mapped to the same object, which means that a book can be read more than once in contrast to writing a book, which is (usually) written only once (Filip 2007: 220). The same holds for verbs like wash and copy, which do not fulfil the condition of the uniqueness of events (Filip 1993/1999: 93). The uniqueness of events can be tested by checking whether the verb can be combined with twice, three times etc. The verb read in (25) can be combined with twice while the verb eat in (26) cannot. Therefore, eat fulfils the condition that we have a unique event and read does not. ${ }^{17}$

Mary read this book twice. \#Mary ate this bread twice.

See Tenny (1994) for the 'measuring-out' of direct internal arguments and her Aspectual Interface Hypothesis. The incremental theme relation is also called the 'ADD TO' relation by Verkuyl (1972, 1993, 1999, 2005), and 'structure-preserving binding' by Jackendoff (1996).

A 'kind' reading for the example in (26) in which Mary ate this kind of bread twice has to be excluded. 


\subsubsection{Aspectual composition}

As already mentioned, the direct object influences the (a)telicity of the whole predication with incremental verbs, which is demonstrated with the verb eat in (27):
a. $\quad$ Mary ate a/the tomato in ten minutes.
b. \#Mary ate tomatoes in ten minutes.
c. \#Mary ate soup in ten minutes.

A telic predication is achieved only in (27a). In (27b, c), we get an atelic predication due to the fact that the incremental theme argument in (27b) is a bare plural and in (27c) a bare mass noun. This can be explained in terms of aspectual composition as in (28):

Aspectual composition of incremental theme predications:

An incremental theme verb combined with a quantized incremental theme argument yields a telic predication whereas combined with a cumulative incremental theme argument it yields an atelic predication. (based on Krifka 1986, 1989: 158, 1992: 31, 1998; Filip 1993/1999, 2001).

There are several means available which give rise to the quantization of a mass or plural object. In (29a), the definite and indefinite article leads to quantization while the same is achieved in (29b) by a numeral construction or a container construction in (29c).
a. Mary ate the tomatoes/a soup in ten minutes.
b. Mary ate five tomatoes in ten minutes.
c. Mary ate a plateful of tomatoes in ten minutes.

Since most Slavic languages do not have articles, they cannot use this quantization strategy (29a) and allow for bare singular count nouns. In contrast to the Germanic languages, the Slavic languages have a grammaticalized aspectual system as was presented for Polish. In Slavic languages, the telicity of incremental theme verbs is dependent on the perfective/imperfective distinction of the verb. With perfective verbs, a telic incremental theme predication is achieved. The examples in (30) differ 
only with respect to the grammatical aspect of the verb. In (30a), the perfective incremental theme verb is combined with a bare count noun which yields a telic predication indicated by the time span adverbial $w$ godzine 'in an hour'. In contrast to (30a), the predication with an imperfective verb in (30b) is atelic ${ }^{.18}$
a. Maria $z$-jadt-a ${ }^{\mathrm{PF}}$ jabtko $w$ godzinę.
Maria Z-eat.PST-F apple in hour
'Maria ate the/an apple in an hour.'
b. Maria jadt-a ${ }^{\mathrm{IMPF}}$ jabtko ( ${ }^{*} w$ godzinę).
Maria eat.PST-F apple in hour
'Maria ate/was eating the/an apple.'

\subsubsection{Filip's approach}

Filip (1993/1999: 3f.) focuses on the interaction of the nominal and the verbal domain and their contribution for achieving a telic predication. ${ }^{19}$ She investigates the impact of the perfective and imperfective aspect as well as verbal affixes on the (in)definite reading of bare noun phrases in the articleless Slavic languages with special emphasis on Czech, but also on Russian (Filip 2005b). She analyses the factors under which a definite interpretation is enforced. As has been shown in section 4.3, a perfective verb by itself does not enforce a definite reading. Filip focuses on perfective and strictly incremental theme verbs and argues that with such verbs definiteness of the direct object is enforced. This is why the concept of incrementality was introduced in the previous section. Before touching on the different factors she proposes, I will present Filip's approach to the perfective aspect. Filip (2005a: 134) analyses the perfective aspect as a totality operator (TOT):

[t] he effect of $T O T(P)$ is to individuate atomic events in the denotation of a perfective verb, given that it is required that no two events in the denotation set of a given predicate $P$ overlap.

Imperfective incremental theme verbs can also lead to a telic predication. See Filip (2004: 105, 109) for the discussion of Russian data and Czardybon \& Fleischhauer (2016) for Polish.

Filip (2004: 93f.) defines the notion of telicity semantically, by assuming that telic verbs have the property of denoting atomic events. 
Intuitively, TOT $(P)$ denotes events each of which is conceived as 'a single whole without distinction of the various phases that make up that situation' (Comrie 1976, p. 16).

The perfective aspect thus expresses single events which are taken as a whole. Given the homomorphism between the event and object for incremental theme verbs and the fact that the perfective aspect expresses total events, Filip (2005a: 134f.) concludes that "the Incremental Theme argument must refer to totalities of objects falling under its description." Totality of objects means that the incremental theme argument has to have a quantized reference, which is the case with singular count nouns. However, with bare mass nouns and bare plurals we have cumulative reference and thus "they do not match the '[TOT+]' requirement imposed on the Incremental Theme argument by a perfective verb" (Filip 1993/1999: 251, 2001: 487). In such cases, the event cannot be delimited by the incremental theme verb and this is why bare plurals and mass nouns are shifted by the totality operator to a totality interpretation, i.e. to the maximal quantity of a mass predicate or the maximal group of a plural predicate (Filip 1993/1999: 247f.) and "[s]uch maximal objects are unique, therefore, anchoring bare plurals and bare mass terms to such maximal objects in the domain of discourse amounts to their having the definite referential interpretation" (Filip 2005a: 136). This shifting leads to a definite interpretation of the direct object, which is, however, only a side effect. With singular count nouns, which are inherently quantized, this shifting is not necessary. This also explains why singular count incremental theme arguments do not necessarily have to be interpreted as definite (Filip 1993/1999: 253) while cumulatively referring direct objects of strictly incremental theme verbs do. This captures the empirical observations made so far very well.

Filip mentions a further factor: definiteness is only enforced if the incremental theme arguments "are not in the scope of other quantificational elements" (Filip 1993/1999: 243). This point is crucial in order to explain sentences such as (31a), a Czech example taken from Filip (1993/1999: 239). In spite of a perfective and strictly incremental theme verb, the direct object has an indefinite reading due to the presence of the accumulative prefix $n a$, which perfectivizes the verb, but also adds 
the quantificational meaning 'a lot of' and requires a "non-specific indefinite interpretation [of the direct object], regardless whether the verb they form is perfective or imperfective" (Filip 2005b: 231). ${ }^{20}$ The same is true for the equivalent Polish sentence in (31b). ${ }^{21}$ This example only differs in the case marking of the direct object. In Polish, verbs with the accumulative $n a$ - require the direct object to be in genitive case while in Czech the accusative or the genitive case can be used. ${ }^{22}$

a. Czech (Filip 1993/1999: 239)

Na-tkala ${ }^{\mathrm{PF}} \quad$ jsem plátno.

ACM-weave.PST AUX cloth.SG.ACC

'I weaved a lot of cloth.'

b. Polish

Na-tka-t-em ${ }^{\mathrm{PF}} \quad$ tkanin-y $\quad /{ }^{*}$ tkanin-ę.

ACM-weave-PST-1SG cloth-SG.GEN / cloth-SG.ACC

'I weaved a lot of cloth.'

Filip $(1993 / 1999,2001)$ shows that aspect as a definiteness strategy has been over-estimated because not every perfective verb automatically leads to a definite reading of the direct object. The definite interpretation is a side effect of the totality operator of perfective aspect; equating the function of the definite article for object NPs and perfective aspect is inadequate.

\subsubsection{Evidence against the equation of definiteness and perfectivity}

Empirical support against equating definiteness and perfective aspect is furthermore offered by Czardybon \& Fleischhauer (2014), who investigate Bulgarian and the Polish dialect Upper Silesian. These two lan-

\footnotetext{
20 The accumulative $n a-$ and delimitative $p o$ - are called measure prefixes by Filip (2005b).

For a detailed analysis of the accumulative prefix $n a$ - in Polish see Piernikarski (1969: 94) and in particular Piñón (1994), for Czech see Filip (1993/1999: 229f., 261f., 2005b), and for Russian see Birkenmaier (1977: 402f.).

Filip (1993/1999: 266, note 6) stresses that in Czech the accusative is preferred especially by younger speakers and that the genitive is regarded as archaic.
} 
guages have a grammaticalized aspectual system, like the other Slavic languages, but they also have a grammaticalized definite article like the Germanic languages. The authors analyse the strategies that achieve a telic incremental theme predication. They show that with perfective strictly incremental theme verbs, cumulative objects have to be explicitly quantized, for example, by a definite article, to yield a telic predication. This is shown by the Upper Silesian example (32d) and Bulgarian example in (33d). Otherwise, the constructions only allow for a kind reading and are atelic (32c)/(33c). The imperfective verb only leads to an atelic predication, irrespectively of the presence $(32 b) /(33 b)$ or absence of the definite article (32a)/(33a).

(32) Upper Silesian (Czardybon \& Fleischhauer 2014: 388-389)
a. Łon jod $^{\mathrm{MPF}}$ jabk-o ( ${ }^{*} z a$ godzina).
he eat.PST apple-ACC.SG ( in hour)
'He ate/was eating an apple.'
b. Łon jod $^{\mathrm{MPF}}$ te jabk-o ( ${ }^{*}$ za godzina).
he eat.PST DEF apple-ACC.SG ( in hour)
'He ate/was eating the apple.'
c. \#Łon $z$-jod ${ }^{\mathrm{PF}}$ jabk-a.
he Z-eat.PST apple-ACC.PL
'He ate [some plurality of the kind] apples.'
d. Eon $z$-jod $^{\mathrm{PF}}$ te jabk-a za godzina
he Z-eat.PST DEF apple-ACC.PL in hour
'He ate the apples in an hour.'

(33) Bulgarian (Czardybon \& Fleischhauer 2014: 388-389)
a. Marija jade ${ }^{\mathrm{IMPF}}$ jabălkal jabălkil kaša ( ${ }^{*} z a$ edin čas).
Maria ate apple.SG/ apple.PL/ mash in one hour
'Maria ate/was eating an apple/apples/mash.'
b. Marija jade ${ }^{\mathrm{IMPF}}$ jabălka-ta (' $z$ a edin čas).
Maria ate apple.SG-DEF in one hour
'Maria ate/was eating the apple.'
c. \#Marija iz-jade jabălki.
Maria IZ-ate apple.PL
'Maria ate [some plurality of the kind] apples.' 
d. Marija iz-jade $e^{\mathrm{PF}}$ jabălki-te za edin čas. Maria IZ-ate apple.PL-DEF in one hour 'Maria ate the apples in one hour.'

The examples in (32) and (33) show that in Upper Silesian and Bulgarian the definite article alone is not sufficient to yield a telic predication, and thus differs from the Germanic languages. However, Upper Silesian is not like the articleless Slavic languages either since the combination of a perfective incremental verb and a bare mass noun does not yield a telic interpretation. On the basis of these data, Czardybon \& Fleischhauer (2014) provide arguments against the assumption that the perfective aspect and the definite article have the same semantic functions and that they do not mark the same, as is claimed by Abraham (1997: 60) for Bulgarian.

\subsection{Definiteness conditions - Polish data and analysis}

So far, Filip's approach accounts for the definiteness enforcement with strictly incremental theme verbs. Her analysis also holds for the Polish strictly incremental theme verbs given in section 4.3. In the following, two major questions will be discussed. First, is Filip's generalization true of all strictly incremental theme verbs of Polish (section 4.5.1)? Second, do we find non-strictly incremental theme verbs with which definiteness of the direct object is also enforced (4.5.2)? Filip only focuses on strictly incremental theme verbs and allows for the possibility that there are further factors that may contribute to the definite interpretation of NPs with other classes of verbs.

\subsubsection{Strictly incremental theme verbs}

If one looks for the combination of a perfective and strictly incremental theme verb combined with a bare mass NP in the National Corpus of Polish, one comes across examples in which the direct object is interpreted as indefinite. This is especially the case with the mass nouns piwo 
'beer', kawa 'coffee', herbata 'tea', and zupa 'soup', less so with miód 'honey', mięso 'meat', and cukier 'sugar'. This is illustrated by the following example in which the perfective and strictly incremental theme verb wypic 'drink' is combined with the bare mass noun piwo 'beer'. The noun does not have a definite reading as would be expected, but rather an indefinite reading. The preceding context of the sentence is that a man is stopped by the police.

Wykazało 0,6 promila w wydychanym przez niego

proved 0.6 alcohol level in exhaled by him

powietrzu. Mieszkaniec Rzecht-y miat przyznać

air inhabitant Rzechta-GEN had admit

policjant-om, $\dot{z} e \quad w y-p i-t^{\mathrm{PF}} \quad$ piwo $i$ sto

policemen-DAT that WY-drink-PST beer and hundred

gram-ów wódk-i. ${ }^{\mathrm{C}}$

gram-GEN vodka-GEN

'An alcohol level of 0.6 in his exhaled air was proven. The inhabitant of Rzechta admitted to the policemen that he had drunk some (delimited quantity of) beer and a hundred grams of vodka.'

How can this indefinite reading be explained? According to Filip (p.c.), the interpretation of wypit piwo in the above context involves an implicit nominal measure phrase "a delimited quantity of beer", and what the quantity might be here capitalizes on our knowledge that beer is drunk in certain well-known conventional portions like glasses or bottles. Wódka 'vodka' in (34) occurs in a nominal measure construction with the measure phrase sto gramów 'hundred grams'. So the parallel to the explicit nominal measure phrase hundred grams may also be seen as supporting the presence of an implicit nominal measure phrase "[a delimited quantity of] beer". The presence of this implicit nominal measure phrase makes the interpretation of beer quantized, and hence exempt from further quantization stemming from the perfective aspect of the verb. With a quantized reference, they match the totality requirement imposed by the perfective aspect just like singular count nouns. Thus, they also allow for an indefinite interpretation which explains the data presented above. 
What still needs to be done is to check strictly incremental perfective theme verbs other than drink and eat in Polish such as wypalić 'smoke', napisać 'write', stworzyć 'create', and spalić 'burn', and see if a definite interpretation is achieved. In (35), the bare plural papierosy 'cigarettes' only allows for a definite interpretation with the perfective and strictly incremental theme verb wypalić 'smoke'. The same is true for the mass noun mięso 'meat' with the perfective verb zjeść 'eat'.

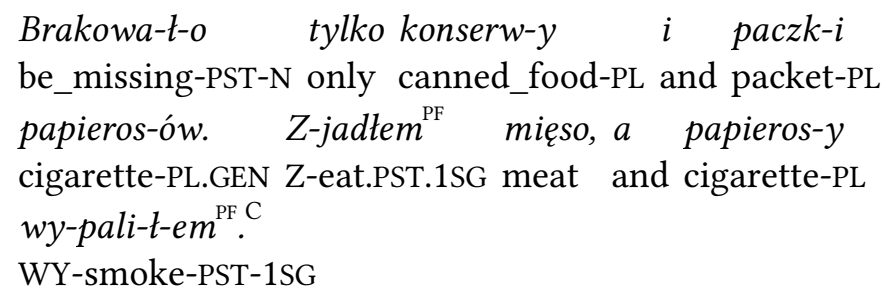

'Only canned food and cigarette packets were missing. I had eaten the meat and smoked the cigarettes.'

Another example of a strictly incremental theme verb is spalic 'burn'. The perfective verb spalic combined with the plural noun listy 'letters' leads to a definite interpretation of the direct object, while the imperfective equivalent allows for a definite as well as an indefinite reading of the direct object, depending on the context.
a. Jan s-pali- $t^{\mathrm{PF}} \quad$ list $-y$.
Jan S-burn-PST letter-PL.ACC
'Jan burnt the letters.'
b. Jan pali-t I $^{\mathrm{MPF}}$ list-y.
Jan burn-PST letter-PL.ACC
'Jan burnt/was burning (the) letters.'

This shows that bare plurals and mass nouns also enforce definiteness with other strictly incremental theme verbs.

In the following, I will discuss how the addition of different prefixes to a strictly incremental theme verb affects the (in)definite interpretation 
of the incremental theme argument. ${ }^{23}$ The addition of the terminative prefix $d o$ - to the strictly incremental theme verbs pić 'drink' and jeść 'eat' also gives rise to a definite reading of the direct object. The bare plural truskawki 'strawberries' (37a) and mass nouns zupa 'soup' (37a) and herbata 'tea' (37b) only allow for a definite reading.
a. Do-jadt-em ${ }^{\mathrm{PF}}$ zup-el truskawk-i.
DO-eat.PST-1SG soup-SG.ACC strawberry-PL.ACC
'I finished eating the soup/the strawberries.'
b. Do-pi-t-em ${ }^{\mathrm{PF}}$ herbat-ę.
DO-drink-PST-1SG tea-SG.ACC
'I finished drinking the tea.'

The prefix $w y$ - in combination with jeść 'eat' also leads to a definite reading of the direct object. However, there is a restriction with respect to the direct object: a singular count noun cannot be combined with this prefix and verb form since a cumulatively referring NP is required. This is not the case with singular count nouns.

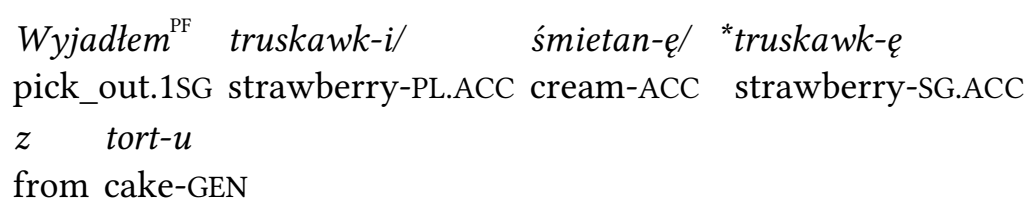

'I picked out and ate (all) the strawberries/the cream from the cake.'

Focusing on Russian, Filip (2005b: 229, 242, 270) shows that measure prefixes such as the delimitative $p o-$ and accumulative $n a$ - induce an indefinite and require a cumulative incremental theme argument. Thus, Filip demonstrates that not all prefixes that are combined with strictly incremental theme verbs such as eat and drink lead to a definite interpretation of the direct object. The Polish example in (39) is taken from Fleischhauer \& Czardybon (2016), who investigate the role of Polish verbal prefixes and German particles in aspectual composition. The delimi-

Filip (1992: 142f.) shows that there are prefixes that lead to an indefinite interpretation of direct objects with strictly incremental theme verbs. She gives Czech examples and claims that this is also the case in other Slavic languages. 
tative prefix po- perfectivizes the verb and adds the meaning that the event took place for a while. Filip's (2005b) observation explains the Polish data in (39). (39a) is grammatical because the direct object is cumulative, whereas (39b) is ungrammatical due to the quantized direct object resulting from a container construction (Filip 1992). ${ }^{24}$

$$
\begin{array}{ll}
\text { a. } & \text { Po-pi-t-em }{ }^{\mathrm{PF}} \quad \text { herbat-y. } \\
\text { DEL-drink-PST-1SG tea-GEN } \\
\text { 'I drank tea for a while.' } \\
\text { b. }{ }^{*} \text { Po-pi-t-em }{ }^{\mathrm{PF}} \text { szklank-e herbat-y. } \\
\text { DEL-drink-PST-1SG glass-ACC tea-GEN } \\
\text { (Fleischhauer \& Czardybon 2016) }
\end{array}
$$

(39b) shows that the delimitative prefix is not compatible with a direct object that is quantized due to the container construction szklanka 'glass'. Fleischhauer \& Czardybon (2016) explain the data in (39) by arguing that delimitative po- individuates the event by measuring the running time and not the quantity of the incremental theme argument as is the case with wypić and zjeść. With the perfective verb popić, the event is regarded as total with respect to the temporal duration. This is sufficient for the individuation of the event, and the total consumption of the direct object is not required, which explains why popić allows a cumulative direct object.

This shows that the semantic content of the prefix influences the (in)definite reading of the direct object, and not every prefix leads to a perfective strictly incremental theme verb which requires a definite reading of the bare plural or mass noun as direct object.

24 Popić can also have other meanings. Without a direct object popić means 'to get drunk'. With a direct object in the accusative case, it means 'to swallow (down)' as in (i).

(i) Jan po-pit $\mathrm{PF}^{\mathrm{F}}$ tabletk-e wod-a.

Jan PO-drank pill-ACC water-INS

'Jan swallowed (down) the pill with water.' 


\subsubsection{Incremental and non-incremental theme verbs}

In this section, I want to focus on incremental and non-incremental verbs and investigate whether they enforce definiteness. The difference between strictly incremental and incremental theme verbs is that with the latter the referent of the incremental theme argument can be affected more than once. An apple can only be eaten once, but a book can be read more than once. This is why the verb eat is strictly incremental while read is only incremental. For Polish, it seems that with all incremental theme verbs the direct object is also interpreted as definite. The example in (40) is taken from Piñón (2001: 397), who shows that with the perfective verb przeczytać 'read' in (40b) only a definite reading of the incremental theme argument artykuty 'articles' is possible, which is also confirmed by my informants. For the direct object of the imperfective verb in (40a), he gives only an indefinite reading as a possible interpretation while according to my informants a definite interpretation is also possible, which has been added in the translation.
a. Basia czyta-t-a ${ }^{\mathrm{IMPF}}$ artykut-y.
Basia read-PST-F article-PL.ACC
'Basia read (the) articles.'
b. Basia prze-czyta-t-a $a^{\mathrm{PF}}$ artykut-y.
Basia PRZE-read-PST-F article-PL.ACC
'Basia read the articles.'
(after Piñón 2001: 397)

This example demonstrates that definiteness can also be enforced with incremental theme verbs, but only if the incremental theme argument is cumulative as in (40). With singular count nouns, a definite as well as indefinite interpretation is possible (41), just like with strictly incremental theme verbs:

$$
\begin{aligned}
& \text { Jan prze-czyta- } \ell^{\mathrm{PF}} \quad \text { list. } \\
& \text { Jan PRZE-read-PST letter.SG.ACC } \\
& \text { 'Jan read a/the letter.' }
\end{aligned}
$$


The same effect can be observed with other incremental theme verbs such as skopiować 'to Xerox/photocopy'. A possible explanation of why a definite interpretation of the incremental theme argument is enforced with such verbs, too, is that the individuation of the event is achieved by measuring the quantity of the incremental theme argument. Here, too, a quantized incremental theme argument is required to individuate the event. In case of a cumulative noun, the event cannot be individuated, which leads to the quantization of the direct object. As a side effect, the direct object gets a definite interpretation. We are dealing with the same situation as with strictly incremental theme verbs.

I would now like to discuss verbs which are not incremental. The difference between incremental and non-incremental theme verbs is that incremental theme verbs provide a homomorphism between the event and the incremental theme argument. This is not the case with nonincremental theme verbs such as bring an apple. If half of the bringing event is over this does not mean that half of the apple is brought.

I divide the non-incremental theme verbs into two groups. One group of verbs enforces the definite reading of the direct object and the other does not. In the following, I will investigate these two groups and will try to find the factors that are responsible for their different behaviour.

The perfective verbs in (42) kupić 'buy' and znaleźć 'find' are not incremental and do not enforce a definite reading of bare mass nouns (42a), bare plurals (42b), or bare singular count nouns (42c). In all three examples, the direct objects can be interpreted as definite or indefinite, which is dependent on the context.
a. Jan kupi- $\mathbb{P}^{\mathrm{PF}}$ mlek-o.
Jan buy-PST milk-ACC
'Jan bought (the) milk.'
b. Jan znalazt ${ }^{\mathrm{PF}} w$ plecak-u cukierki.
Jan find.PST in backpack-LOC sweet.PL.ACC
'Jan found (the) sweets in the backpack.'
c. Jan kupi- $t^{\mathrm{PF}}$ jabtk-o.
Jan buy-PST apple-SG.ACC
'Jan bought the/an apple.' 
There are many other perfective non-incremental theme verbs which do not enforce definiteness of their direct objects, e.g. dać 'give', poczuć 'smell', przyniessć 'bring', ustyszeć 'hear', wygrać 'win', wziać 'take', zamówić 'order', zauważyć 'notice', to mention only a few. Among these verbs we find many verbs of perception and verbs which are found in Levin's (1993:138) class called 'Verbs of Change of Possession'.

The second group of verbs imposes definiteness on the direct object. An example is given in $(43)^{25}$. In (43b), only a definite reading of the bare plural ziemniaki is possible, whereas in (43a) the direct object also allows for a definite reading rather than only indefinite as claimed by Sadziński. The verb in (43b) is combined with the distributive prefix po-, which has the meaning 'one by one'.
a. Waż-t-em ${ }^{\mathrm{IMF}}$ ziemniak-i.
weigh-PST-1SG potato-PL.ACC
'I weighed/was weighing (the) potatoes.'
b. $\quad$ Po-waży- $t-\mathrm{em}^{\mathrm{PF}} \quad$ ziemniak-i.
DISTR-weigh-PST-1SG potato-PL.ACC
'I weighed the potatoes one by one.'

Here again one could ask why only a definite reading is available in (43b). Is this due to the verb or due to the distributive prefix po-? It was shown above that the prefixes have an influence on the direct object. In (44), the most neutral prefix for the verb ważyć 'weigh' was chosen. What can be observed is that the change of the prefix does not change the fact that the direct object only allows for a definite reading.

$$
\begin{aligned}
& \text { Z-waży-t-em }{ }^{\mathrm{PF}} \quad \text { ziemniak-i. } \\
& \text { Z-weigh-PST-1SG potato-PL.ACC } \\
& \text { 'I weighed the potatoes.' }
\end{aligned}
$$

There are also other perfective non-incremental theme verbs which enforce the definiteness of the direct object. The same effect can be observed with the following verbs: otworzyć 'open', udowodnić 'prove', wtączyć 'turn on', zarezerwować 'reserve', zorganizować 'organize',

25 This example is taken from Sadziński (1995/6: 87), but the translation was changed. 
among many others. Here, too, definiteness is only imposed if the direct object is a bare plural (45a) or mass noun. Otherwise it can have an indefinite reading $(45 b)$.
a. Artur otworzy- $\ell^{\mathrm{PF}}$ okn-a.
Artur open-PST window-PL.ACC
'Artur opened the windows.'
b. Artur otworzy- $\boldsymbol{\ell}^{\mathrm{PF}}$ okn-o.
Artur open-PST window-SG.ACC
'Artur opened a/the window.'

It seems to be the case that with verbs such as in (45a) the individuation of the total event is achieved by measuring out the referent of the direct object. This is why the direct object is quantized and, as a side effect, achieves definiteness. With other verbs such as those given in (42) this is not the case. However, it is difficult to find a feature which would predict which verbs enforce the definiteness of the direct object and which do not.

\subsection{Aspect, definiteness, and concept types}

In this section, I want to discuss the question whether the concept type approach by Löbner $(1985,2011)$ is relevant for aspect. This is, in turn, linked to the question whether his noun classification plays a role for the definite or indefinite interpretation of the direct object. As shown in this chapter, the mass/count distinction is of crucial importance. According to Löbner (2015), the properties of inherent relationality and inherent uniqueness are independent of the mass/count distinction illustrated in the following table:

\begin{tabular}{|l|l|l|l|l|}
\hline & \multicolumn{1}{|c|}{ SN } & \multicolumn{1}{c|}{ RN } & IN & \multicolumn{1}{c|}{ FN } \\
\hline Mass noun & water & baggage & air & skin \\
\hline Count noun & book & brother & sun & mother \\
\hline
\end{tabular}

Table 13: Classification of nouns based on

Löbner (2015). 
If we assume that there are mass nouns which are inherently unique, as claimed by Löbner (2015), then the concept type distinction would play a role. We should avoid them in this analysis since they are definite due to their semantics and independent of the factors which enforce the definiteness of the direct object. Only underlyingly [-U] mass nouns should be used as direct objects in order not to blur the picture as to which conditions have to be fulfilled for the enforcement of definiteness. However, this problem may not actually arise, as authors such as Gamerschlag \& Ortmann (2007) argue that there are no underlying non-shifted [+U] mass nouns. In order to determine the underlying concept type of a noun in Polish, Czardybon \& Horn (2015) make use of the test given in (46).

$$
\begin{aligned}
& \text { To jest ' } x \text { ' } i \text { to jest tez ' } x \text { ' } \\
& \text { DEM COP } \mathrm{x} \text { and DEM COP also } \mathrm{x} \\
& \text { 'This is } \mathrm{x} \text { and this is also } \mathrm{x} \text { ' (Czardybon \& Horn, 2015) }
\end{aligned}
$$

The question is whether the two equal NPs that replace the two ' $\mathrm{x}$ ' in (46) can refer to two distinct referents. If this is possible, then the noun is not an underlying [+U] concept type. For instance, if we insert the noun samochód 'car' in (46), the two NPs samochód can only refer to two distinct cars. This is not possible if we use the noun stonce 'sun', since we only have one sun we can refer to, leading to the result that stonce 'sun' is $[+\mathrm{U}]$. This test works perfectly for count nouns. However, the underlying concept type of mass nouns cannot be determined by the test. If we use the mass noun powietrze 'air', it is unclear whether we can refer to two distinct referents or not, because 'air' does not have boundaries. This is why it seems not to be possible to test whether there are underlying $[+\mathrm{U}]$ mass nouns in Polish.

\subsection{Conclusion}

This chapter has shown that not every perfective verb automatically leads to a definite reading of the direct object in Polish, rather that there are special conditions which have to be fulfilled. First, the definiteness 
enforcement is only observable if the direct object is cumulative (cf. Wierzbicka 1967, Krifka 1989, Filip 1993/1999) and is not interpreted as an implicit measure phrase (Filip, p.c.). Second, the definiteness effect is also dependent on the verb itself, such as with incremental theme verbs. Even with some non-incremental theme verbs definiteness is enforced. However, it was not possible to find an explanation why some nonincremental theme verbs have this effect on the direct object and others do not. Third, the semantic content of the prefixes which perfectivize the verb is crucial. Some prefixes such as the accumulative $n a-$ or delimitative po- do not enforce a definite reading of the direct object (cf. Filip 1992, 2005b). 